\title{
openheart Added sugars drive coronary heart disease via insulin resistance and hyperinsulinaemia: a new paradigm
}

\author{
James J DiNicolantonio, James H OKeefe
}

\begin{abstract}
To cite: DiNicolantonio JJ, OKeefe JH. Added sugars drive coronary heart disease via insulin resistance and hyperinsulinaemia: a new paradigm. Open Heart 2017;4:e000729. doi:10.1136/ openhrt-2017-000729
\end{abstract}

Accepted 7 November 2017

\section{CrossMark}

Saint Luke's Mid America Heart Institute, University of Missouri, Kansas City, Missouri, USA

Correspondence to Dr James J DiNicolantonio; jjdinicol@gmail.com
'I know of no single acceptable study that shows a high intake of sugar in a population that is almost entirely free from heart disease. ${ }^{1}$-John Yudkin

Coronary heart disease (CHD) is responsible for one in every six deaths in the USA, ${ }^{2}$ and it eventually manifests as an acute myocardial infarction (MI). In the USA, almost 1 million acute MIs occur each year ${ }^{2}$ with approximately $15 \%$ of patients dying as a result of their acute event. ${ }^{2}$ If one manages to survive an acute MI, depending on the age of onset, the average survival time ranges anywhere from just 3.2 years to up to 17 years. ${ }^{2}$ Thus, CHD and acute MI are leading causes of early mortality in the USA. ${ }^{2}$

Asymptomatic hyperglycaemia is a risk factor for cardiovascular disease (CVD) and CHD, as well as death from CHD. ${ }^{3}$ Hyperglycaemia can develop during an acute MI, even in patients without diabetes, ${ }^{3}$ which may be caused by an increase in catecholamines, a reduction in the release of insulin, development of insulin resistance and increases in cortisol and growth hormone. ${ }^{3-5}$ However, many patients with MI already have diabetes and simply have yet to be diagnosed (ie, latent diabetes), where the acute stress worsens their diabetic state leading to hyperglycaemia. ${ }^{3}$ Indeed, one study showed that $73 \%$ of patients presenting with an acute MI have abnormal glucose tolerance, with $50 \%$ having diabetes. ${ }^{6}$ After 6 months, $43 \%$ still had abnormal glucose tolerance, which is approximately threefold higher than that found in matched controls (15\%), the difference between the two being significant. ${ }^{6}$ Thus, hyperglycaemia does not seem to be an acute or temporary finding in patients who have experienced an MI, with many of these patients having continued abnormal glucose tolerance even when followed for several years after their event.

The Whitehall study, a prospective cohort study encompassing 18403 patients, showed that blood glucose after a 2-hour oral glucose tolerance test was related to the age-adjusted CHD mortality after 7.5 years. ${ }^{7}$ In non-diabetics, a 2-hour blood glucose at $96 \mathrm{mg}$ / $\mathrm{dL}$ or higher was associated with a twofold increased risk of CHD mortality. ${ }^{7}$ An elevated insulin response to an oral glucose load has been found in patients with atherosclerosis of the peripheral, cerebral and coronary arteries. ${ }^{89}$ In the Busselton, Australia study, insulin levels 1 hour after ingesting a $50 \mathrm{~g}$ oral glucose load were significantly related to the 6-year CVD incidence and 12-year CVD mortality in men aged 60 and older. ${ }^{10}$ In both the Helsinki policeman study ${ }^{11}$ and the Paris civil servant study, ${ }^{12}$ insulin levels taken in the fasting state after an oral glucose load (75 or $90 \mathrm{~g}$ ) were associated with the occurrence of MI and CHD death 5 years later in men aged 30-59. However, the insulin:glucose ratio had the closest association with CVD. In all three studies, the relationship of insulin with CVD was independent of other covariates, including lipids, blood pressure and blood sugar. ${ }^{13}$ Considering that refined sugar, even when compared with starch, has been found to raise serum insulin levels, ${ }^{14}{ }^{15}$ this provides compelling evidence that overconsuming added sugars (sucrose or high-fructose corn syrup) may lead to an increased risk of CHD through raised insulin levels.

The evidence incriminating insulin and carbohydrate in atherogenesis is strong, and that this scheme would link atherosclerosis with diabetes, obesity, hyperlipaemia, lack of physical exercise, and, possibly, hypertension. ${ }^{16}$ (Stout and Vallance-Owen)

It has been known for over 50 years that people with hypercholesterolaemia and hyperlipaemia generally have abnormal carbohydrate metabolism, with an elevated insulin level often driving their hyperlipidaemia. ${ }^{17}$ Indeed, insulin has been found to increase lipogenesis ${ }^{18}$ and stimulate smooth muscle cell proliferation. ${ }^{19-21}$ 
Hyperinsulinaemia is also an independent risk factor for CHD, ${ }^{10}{ }^{11}$ and insulin resistance predicts future cardiovascular risk. ${ }^{22}{ }^{23}$ Increased levels of insulin are found in multiple disease states, including obesity, coronary artery disease, hypertension, peripheral vascular disease and those with hypertriglyceridaemia. ${ }^{24}$ Thus, any dietary factor that worsens glucose tolerance or promotes insulin resistance will also likely increase the risk of acute MI, CHD and CHD mortality. Considering that a diet high in added sugars (particularly the fructose component) leads to insulin resistance, ${ }^{25-28}$ the overconsumption of added sugars is undoubtedly a contributing factor to CHD and CVD mortality. Indeed, compared with a diet that contains less than $10 \%$ of calories from added sugars, a diet containing $25 \%$ or more calories from added sugars nearly triples the risk for CVD mortality. ${ }^{29}$

Data from animal and human studies have noted that the isocaloric replacement of starch, glucose or a combination of both, with sucrose or fructose, increases fasting insulin levels, ${ }^{14}{ }^{15}$ reduces insulin sensitivity, ${ }^{25-27}$ increases fasting glucose concentrations, ${ }^{30}$ increases glucose and insulin responses to a sucrose $\operatorname{load}^{1415}$ and reduces cellular insulin binding. ${ }^{25}$ In other words, calorie for calorie, consuming added sugars is more harmful than starch or glucose regarding worsening of insulin sensitivity and glucose tolerance. Additionally, feeding rats sucrose leads to impaired glucose tolerance ${ }^{31}$ and adipose tissue that is less sensitive to the effects of insulin. ${ }^{32}{ }^{33}$ Thus, data from animals and humans indicate that overconsuming added sugars drives insulin resistance and hyperinsulinaemia.

During an acute MI, the heart switches from primarily using fatty acids as energy to using glucose. As insulin facilitates glucose uptake into cells, patients with insulin resistance during an acute MI will have a worse prognosis. Indeed, the degree of insulin resistance is related to the severity of an MI, ${ }^{34}$ and after an MI diabetics are more likely to die compared with non-diabetics. ${ }^{35} \mathrm{~A}$ diet high in added sugars promotes insulin resistance and diabetes, ${ }^{1415283637}$ and thus may lead to larger MIs and increase the risk of CHD mortality.

It is well known that those with diabetes have a higher risk of mortality and MI versus those without diabetes, ${ }^{38}$ which is independent of smoking status, cholesterol levels, blood pressure and body fat distribution. Additionally, patients diagnosed as being newly diabetic also have an increased risk of MI. Diabetics also have more coronary atherosclerosis than non-diabetics, ${ }^{39} 40$ particularly a higher frequency of severe narrowing of the left main coronary artery and healed transmural ventricular scars. ${ }^{41}$ The Framingham study showed that those with diabetes have an approximate threefold increased risk of dying from CVD versus the general population as well as an increased risk of stroke, CHD and peripheral arterial disease. ${ }^{42}$ Higher blood pressure or higher lipoproteins did not account entirely for the increased incidence of CHD among diabetics. ${ }^{13}$

A diet high in added sugars has been shown to increase the prevalence of diabetes, whereas a lower intake has the opposite effect. ${ }^{43-46}$ Thus, added sugars promote an increased risk of CHD by increasing the risk of diabetes, which has been shown in both ecological analyses as well as clinical trial data. Considering that added sugars also promote insulin resistance, and those who experience an acute MI are more likely to be insulin resistant, the overconsumption of added sugars drives CHD. ${ }^{25} 27$

A raised cholesterol level is not the only risk factor in those with CHD. Indeed, many other abnormalities commonly occur such as elevated glucose, insulin, triglycerides, uric acid and lower levels of high-density lipoprotein cholesterol. ${ }^{47}$ Additionally, impaired glucose tolerance, insulin resistance and altered platelet function are commonly found in patients with CHD or those with risk factors for CHD. ${ }^{48-51}$ All of these CHD abnormalities are induced or worsened in humans and animals when given a diet high in sugar, ${ }^{5-55}$ which can be reversed when reverting back to a diet low in sugar. ${ }^{145}$ This provides compelling evidence that the overconsumption of added sugars is a principal driver of CHD.

Administration of a diet high in sugar for just a few weeks leads to approximately one-third of men experiencing numerous changes seen in CHD and peripheral vascular disease..$^{53}{ }^{54}$ These suggest that the overconsumption of sugar and the subsequent insulin resistance and/or hyperinsulinaemia drive CHD as well as other diseases such as hypertension, diabetes, obesity and gout. ${ }^{567}$ Interestingly, smoking, which is a risk factor for heart disease, has been found to induce hyperinsulinism, ${ }^{58}$ suggesting that both the overconsumption of added sugars and smoking predispose to heart disease in a similar manner (via hyperinsulinaemia; although both also induce inflammation, oxidative stress and increased platelet adhesiveness). ${ }^{59-61}$

Over the past 200 years, the average intake of added sugars has increased from 4 to $120 \mathrm{lb} /$ year. $^{62}$ Sugar is even more rewarding than cocaine in animal studies, and in humans added sugar is arguably the most widely consumed addictive substance around the world. ${ }^{63}$ The fact that diabetics have an increased risk of occlusive arterial disease, ${ }^{24}$ and that non-diabetic patients with vascular disease have raised insulin levels, ${ }^{24}$ suggests that insulin resistance is at the centre of heart disease. Considering a diet high in added sugars can induce insulin resistance and hyperinsulinaemia in humans, and a reduction in added sugars can improve these metabolic derangements, there is compelling evidence that the overconsumption of added sugars (high-fructose corn syrup and sucrose) is a principal driver of CHD. Indeed, refined sugar, as compared with fat, starch, glucose, or a combination of starch and glucose, promotes greater detriments on glucose and insulin levels in humans. ${ }^{1415283637}$

Currently, the main dietary culprit thought to lead to CHD is saturated fat. However, the overconsumption of added sugars (sucrose or table sugar and high-fructose corn syrup) has also been associated with an increased risk of CVD and mortality from cardiovascular causes. A diet high in added sugars for just a few weeks has 
been found to produce numerous abnormalities found in patients with CHD including elevated insulin levels and insulin resistance. More importantly, a diet low in added sugars and refined carbohydrates has been found to reverse all of these metabolic defects. The evidence indicates that added sugars are a likely dietary culprit leading to CHD.

Contributors JJD performed the literature search and wrote the initial manuscript. J0 edited and revised the final manuscript.

Competing interests JJD is the author of The Salt Fix.

Provenance and peer review Not commissioned; internally peer reviewed.

Open Access This is an Open Access article distributed in accordance with the Creative Commons Attribution Non Commercial (CC BY-NC 4.0) license, which permits others to distribute, remix, adapt, build upon this work non-commercially, and license their derivative works on different terms, provided the original work is properly cited and the use is non-commercial. See: http://creativecommons.org/ licenses/by-nc/4.0/

(c) Article author(s) (or their employer(s) unless otherwise stated in the text of the article) 2017. All rights reserved. No commercial use is permitted unless otherwise expressly granted.

\section{REFERENCES}

1. Yudkin J. Dietetic aspects of atherosclerosis. Angiology 1966;17:127-33

2. Roger VL, Go AS, Lloyd-Jones DM, et al. Heart disease and stroke statistics--2012 update: a report from the American Heart Association. Circulation 2012;125:e2-e220.

3. Alajbegovic S, Metelko Z, Alajbegovic A, et al. Hyperglycemia and acute myocardial infarction in a nondiabetic population. Diabetologia Croatica 2003;32:169-74.

4. Leor J, Nesto RW, Kloner RA. Acute myocardial infarction and diabetes mellitus. Cardiovasc Res 1993;27:1913-5.

5. Opie LH. Metabolism of free fatty acids, glucose and catecholamines in acute myocardial infarction. Relation to myocardial ischemia and infarct size. Am J Cardiol 1975;36:938-53.

6. Sowton E. Cardiac infarction and the glucose-tolerance test. Br Med J 1962;1:84-6.

7. Fuller JH, Shipley MJ, Rose G, et al. Coronary-heart-disease risk and impaired glucose tolerance. The Whitehall study. Lancet 1980;1:1373-6.

8. Stout RW. The relationship of abnormal circulating insulin levels to atherosclerosis. Atherosclerosis 1977;27:1-13.

9. Stout RW. Diabetes and atherosclerosis-the role of insulin. Diabetologia 1979;16:141-50.

10. Welborn TA, Wearne K. Coronary heart disease incidence and cardiovascular mortality in Busselton with reference to glucose and insulin concentrations. Diabetes Care 1979;2:154-60.

11. Pyöräla K. Relationship of glucose tolerance and plasma insulin to the incidence of coronary heart disease: results from two population studies in Finland. Diabetes Care 1979;2:131-41.

12. Ducimetiere P, Eschwege E, Papoz L, et al. Relationship of plasma insulin levels to the incidence of myocardial infarction and coronary heart disease mortality in a middle-aged population. Diabetologia 1980;19:205-10.

13. Stout RW. Blood glucose and atherosclerosis. Arteriosclerosis 1981;1:227-34.

14. Reiser S, Handler HB, Gardner LB, et al. Isocaloric exchange of dietary starch and sucrose in humans. II. Effect on fasting blood insulin, glucose, and glucagon and on insulin and glucose response to a sucrose load. Am J Clin Nutr 1979;32:2206-16.

15. Reiser S, Michaelis OE, Cataland S, et al. Effect of isocaloric exchange of dietary starch and sucrose in humans on the gastric inhibitory polypeptide response to a sucrose load. Am J Clin Nutr 1980;33:1907-11.

16. Stout RW, Vallance-Owen J. Insulin and atheroma. Lancet 1969;1:1078-80.

17. Waddell WR, Geyer RP, Hurley N, et al. Abnormal carbohydrate metabolism in patients with hypercholesterolemia and hyperlipemia. Metabolism 1958;7:707-16.

18. Kersten S. Mechanisms of nutritional and hormonal regulation of lipogenesis. EMBO Rep 2001;2:282-6.
19. Stout RW, Bierman EL, Ross R. Effect of insulin on the proliferation of cultured primate arterial smooth muscle cells. Circ Res 1975;36:319-27.

20. Pfeifle B, Ditschuneit HH, Ditschuneit H. Insulin as a cellular growth regulator of rat arterial smooth muscle cells in vitro. Horm Metab Res 1980;12:381-5.

21. Pfeifle B, Ditschuneit $\mathrm{H}$. Effect of insulin on growth of cultured human arterial smooth muscle cells. Diabetologia 1981;20:155-8.

22. Venkataraman $\mathrm{K}$, Khoo CM, Leow MK, et al. New measure of insulin sensitivity predicts cardiovascular disease better than HOMA estimated insulin resistance. PLoS One 2013;8:e74410.

23. Gast KB, Tjeerdema N, Stijnen T, et al. Insulin resistance and risk of incident cardiovascular events in adults without diabetes: metaanalysis. PLoS One 2012; 7:e52036.

24. Elkeles RS. Insulin and atheroma. Lancet 1969;1:1211-1212.

25. Beck-Nielsen $\mathrm{H}$, Pedersen $\mathrm{O}$, Lindskov $\mathrm{HO}$. Impaired cellular insulin binding and insulin sensitivity induced by high-fructose feeding in normal subjects. Am J Clin Nutr 1980;33:273-8.

26. Gutman RA, Basílico MZ, Bernal CA, et al. Long-term hypertriglyceridemia and glucose intolerance in rats fed chronically an isocaloric sucrose-rich diet. Metabolism 1987;36:1013-20.

27. Pagliassotti MJ, Shahrokhi KA, Moscarello M. Involvement of liver and skeletal muscle in sucrose-induced insulin resistance: doseresponse studies. Am J Physiol 1994;266:R1637-44.

28. Stanhope KL, Schwarz JM, Keim NL, et al. Consuming fructosesweetened, not glucose-sweetened, beverages increases visceral adiposity and lipids and decreases insulin sensitivity in overweight/ obese humans. J Clin Invest 2009;119:1322-34.

29. Yang Q, Zhang Z, Gregg EW, et al. Added sugar intake and cardiovascular diseases mortality among US adults. JAMA Intern Med 2014;174:516-24.

30. Dunnigan MG, Fyfe T, McKiddie MT, et al. The effects of isocaloric exchange of dietary starch and sucrose on glucose tolerance, plasma insulin and serum lipids in man. Clin Sci 1970;38:1-9.

31. Cohen AM, Teitelbaum A. Effect of dietary sucrose and starch on oral glucose tolerance and insulin-like activity. Am J Physiol 1964;206:105-8.

32. Vrana ASZ, Kazdova L, Fabry P. Insulin sensitivity of adipose tissue on serum insulin concentrations in rats fed sucrose and starch diets. Nutr Rep 1971:31-7.

33. Bruckdorfer KR, Kang SS, Yudkin J. Insulin sensitivity of adipose tissue of rats fed with various carbohydrates. Proc Nutr Soc 1974;33:4a-5.

34. Opie LH, Stubbs WA. Carbohydrate metabolism in cardiovascular disease. Clin Endocrinol Metab 1976;5:703-29.

35. Soler NG, Pentecost BL, Bennett MA, et al. Coronary care for myocardial infarction in diabetics. Lancet 1974;1:475-7.

36. Maegawa $\mathrm{H}$, Kobayashi M, Ishibashi $\mathrm{O}$, et al. Effect of diet change on insulin action: difference between muscles and adipocytes. Am J Physiol 1986;251:E616-23.

37. Hallfrisch J, Ellwood KC, Michaelis OE, et al. Effects of dietary fructose on plasma glucose and hormone responses in normal and hyperinsulinemic men. J Nutr 1983;113:1819-26.

38. Lapidus L, Bengtsson C, Blohmé G, et al. Blood glucose, glucose tolerance and manifest diabetes in relation to cardiovascular disease and death in women. A 12-year follow-up of participants in the population study of women in Gothenburg, Sweden. Acta Med Scand 1985;218:455-62.

39. Robertson WB, Strong JP. Atherosclerosis in persons with hypertension and diabetes mellitus. Lab Invest 1968;18:538-51.

40. Vigorita VJ, Moore GW, Hutchins GM. Absence of correlation between coronary arterial atherosclerosis and severity or duration of diabetes mellitus of adult onset. Am J Cardiol 1980;46:535-42.

41. Waller BF, Palumbo PJ, Lie JT, et al. Status of the coronary arteries at necropsy in diabetes mellitus with onset after age 30 years. Analysis of 229 diabetic patients with and without clinical evidence of coronary heart disease and comparison to 183 control subjects. Am J Med 1980;69:498-506.

42. Garcia MJ, McNamara PM, Gordon T, et al. Morbidity and mortality in diabetics in the Framingham population. Sixteen year follow-up study. Diabetes 1974;23:105-11.

43. Reiser S, Bohn E, Hallfrisch J, et al. Serum insulin and glucose in hyperinsulinemic subjects fed three different levels of sucrose. Am J Clin Nutr 1981:34:2348-58.

44. Basu S, Yoffe P, Hills N, et al. The relationship of sugar to populationlevel diabetes prevalence: an econometric analysis of repeated cross-sectional data. PLoS One 2013;8:e57873.

45. Goran MI, Ulijaszek SJ, Ventura EE. High fructose corn syrup and diabetes prevalence: a global perspective. Glob Public Health 2013;8:55-64. 
46. Gross LS, Li L, Ford ES, et al. Increased consumption of refined carbohydrates and the epidemic of type 2 diabetes in the United States: an ecologic assessment. Am J Clin Nutr 2004;79:774-9.

47. Yudkin J. Sucrose, coronary heart disease, diabetes, and obesity: do hormones provide a link? Am Heart J 1988;115:493-8.

48. Szanto S, Yudkin J. Dietary sucrose and platelet behaviour. Nature 1970;225:467-8.

49. Blake DR, Meigs JB, Muller DC, et al. Impaired glucose tolerance, but not impaired fasting glucose, is associated with increased levels of coronary heart disease risk factors: results from the Baltimore Longitudinal Study on Aging. Diabetes 2004;53:2095-100.

50. Knudsen EC, Seljeflot I, Abdelnoor M, et al. Abnormal glucose regulation in patients with acute ST- elevation myocardial infarction-a cohort study on 224 patients. Cardiovasc Diabetol 2009;8:6.

51. Somani BL, Arora MM, Datta SK, et al. Prevalence of unsuspected glucose intolerance in Coronary Artery Disease (CAD) patients: Importance of HbA1c. Med J Armed Forces India 2013;69:222-7.

52. Bruckdorfer KR, Worcester NA, Yudkin J. Influence of diet on rat platelet aggregation. Nutr Metab 1977;21(Suppl 1):196-8.

53. Szanto S, Yudkin J. The effect of dietary sucrose on blood lipids, serum insulin, platelet adhesiveness and body weight in human volunteers. Postgrad Med J 1969;45:602-7.
54. Yudkin J, Kakkar VV, Szanto S. Sugar intake, serum insulin and platelet adhesiveness in men with and without peripheral vascular disease. Postgrad Med J 1969;45:608-11.

55. Szanto S, Yudkin J. Plasma lipids, glucose tolerance, insulin levels and body-weight in men after diets rich in sucrose. Proc Nutr Soc 1969;28:11a-12.

56. Yudkin J. Diet and coronary heart disease: why blame fat? $J R$ Soc Med 1992;85:515-6.

57. Szanto S, Yudkin J. Insulin and atheroma. Lancet 1969;1:1211-2.

58. Szanto S. Smoking and atherosclerosis. Br Med J 1967;3:178.

59. Lustig RH. Fructose: metabolic, hedonic, and societal parallels with ethanol. J Am Diet Assoc 2010;110:1307-21.

60. Barua RS, Ambrose JA. Mechanisms of coronary thrombosis in cigarette smoke exposure. Arterioscler Thromb Vasc Biol 2013;33:1460-7.

61. Bhatt SP, Dransfield MT. Chronic obstructive pulmonary disease and cardiovascular disease. Trans/ Res 2013;162:237-51.

62. Bray GA, Popkin BM. Dietary sugar and body weight: have we reached a crisis in the epidemic of obesity and diabetes?: health be damned! Pour on the sugar. Diabetes Care 2014;37:950-6.

63. DiNicolantonio JJ, O'Keefe JH, Wilson WL. Sugar addiction: is it real? A narrative review. Br J Sports Med 2017.bjsp orts-2017-097971. [Epub ahead of print 23 Aug 2017]. 